\title{
Clinical Features, Laboratory Characteristics and Prognostic Factors of Severity in Patients with Rickettsiaceae at Two Military Hospitals, Northern Vietnam
}

\author{
Nam Le Van ${ }^{1} *$ \\ Chung Pham $\operatorname{Van}^{2, *}$ \\ Manh Nguyen Dang ${ }^{2}$ \\ Thang Dao Van' \\ Quyen Le T Do' \\ Hung Vu Hoang' \\ Tien Tran Viet ${ }^{1,3}$ \\ Binh Nhu Do (D) $)^{1,4}$ \\ 'Department of Infectious Disease, \\ Military Hospital 103, Vietnam Military \\ Medical University, Ha Noi, Vietnam; \\ ${ }^{2}$ Institute of Clinical Infectious and \\ Tropical Diseases, Military Central \\ Hospital 108, Ha Noi, Vietnam; ${ }^{3}$ Director \\ Office, Military Hospital 103, Ha Noi, \\ Vietnam; ${ }^{4}$ Division of Military Science, \\ Military Hospital I03, Ha Noi, Vietnam \\ *These authors contributed equally to \\ this work
}

This article was published in the following Dove Press journal: Infection and Drug Resistance

Introduction: Rickettsioses are diseases caused by intracellular Gram-negative bacteria of the Rickettsiaceae family and transmitted through the bite of infected ticks or mites.

Aim of Study: To investigate the clinical and subclinical characteristics and prognostic severe factors of the disease caused by Rickettsiaceae.

Methods: A prospective, descriptive cross-sectional study was conducted at Department of Infectious Diseases of two military hospitals in Northern Vietnam from May 2013 to June 2019, in which 88 adult febrile patients caused by Orientia tsutsugamushi (50 patients) or Rickettsia spp. (38 patients) were enrolled. We recorded information regarding epidemiological characteristics (age, geography, residence, occupation), medical history, clinical and subclinical findings, life-threatening complications during treatment, outcomes and some factors predicting serious life-threatening complications in a case record form.

Results: Scrub typhus (ST) patients had eschar (70\%), skin-conjunctiva congestion $(60 \%)$ and lymphadenopathy (44\%). Rickettsia patients had a higher rate of maculopapular rash (39.5\%), no ulcers and no lymphadenopathy detected. The majority of patients had elevated PCT $>0.05 \mathrm{ng} / \mu \mathrm{L}$ and increase in liver enzymes and thrombocytopenia. Major prognostic factors for severe complications included diffuse infiltrates on lung X-ray (OR: 19.5; $\mathrm{p}=$ 0.014 ), coarse crackles (OR: $18 ; \mathrm{p}=0.016$ ), respiratory rate $\geq 25$ cycles/minute (OR: $18 ; \mathrm{p}=$ $0.016)$, shortness of breath (OR: 7.44; $\mathrm{p}=0.003)$, pleural fluid (OR: 4.3; $\mathrm{p}=0.035)$ and increase in AST $\geq 200 \mathrm{UI} / 1$ (OR: 4.42; $\mathrm{p}=0.012$ ). The PCT value is able to distinguish between the two groups with quite high reliability (the area under the ROC curve is 0.75 ).

Conclusion: Eschar and peripheral lymphadenopathy were two valuable clinical symptoms for the diagnosis of scrub typhus and distinguishing 2 groups of diseases. Respiratory distress, increase in AST $\geq 200 \mathrm{UI} / 1$ and level of PCT were used as major prognostic factors in patients with Rickettsiaceae.

Keywords: Rickettsiaceae, Orientia tsutsugamushi, Rickettsia spp., scrub typhus

\section{Introduction}

Rickettsiaceae has long been known to be zoonosis and among the oldest known vector-borne diseases. This is a family of obligatory intracellular bacteria, having diverse biological characteristics and is classified into two major genera. ${ }^{1,2}$ Genus Orientia consists of Orientia tsutsugamushi causing scrub typhus, which has been known since the fourth century before Christ, and Orientia chuto have recently 
been discovered and proven to cause disease in humans. ${ }^{3,4}$ Genus Rickettsia includes two large groups: Typhus group including Rickettsia typhi, which causes endemic typhus (murine typhus) and Rickettsia prowazekii, causes epidemic typhus; Spotted fever group includes many other species of Rickettsia. ${ }^{4,5}$ The Rickettsiaceae were found on every continent except Antarctica. In the US, cases of tickborne diseases increased more than twofold between 2004 and 2017 , from 22,527 to 59,349 , respectively. ${ }^{6}$

In Vietnam, the serum antibody prevalence of Orientia tsutsugamushi causing scrub typhus, Rickettsiatyphi causing murine typhus and other Rickettsia of spotted fever group in the community of northern Vietnam were $1.7 \%$; $6.5 \%$ and $1.1 \%$, respectively. ${ }^{7}$ There have been reports of R. felis causing human illness in central Vietnam. ${ }^{8}$ In the National Hospital for Tropical Diseases, Rickettsioses account for one-third of acute undifferentiated fevers with the mortality rate of $5.4 \%$ between 2015 and $2017 .^{9}$

It is of great challenge to diagnosis Rickettsioses because of the variable clinical manifestations with the typical eschar, rash or lymphadenopathy are not always presented; ${ }^{10-12}$ complications such as pneumonitis, and meningoencephalitis vary from one disease to another. ${ }^{10,12,13}$ Therefore, it is easy to misdiagnose accompanied by complications and higher mortality. ${ }^{12}$ According to CDC, estimated case fatality rate of Rickettsial infection can be up to $5 \%$ to $10 \%{ }^{14}$ and delayed treatment beyond the fifth day of illness is the single most important predictor of fatal outcome. ${ }^{15}$ Misdiagnosis and treatment persist among healthcare providers even in the United State. $^{10}$ In recent report from CDC, only $53 \%$ of patients diagnosed with any rickettsial infection between 2005 and 2016 were treated with doxycycline within 30 days of diagnosis. ${ }^{16}$

An in-depth understanding of clinical, subclinical characteristics and prognostic factors of the disease caused by Rickettsiaceae will help clinicians promptly diagnose with appropriate treatment, minimize complications and improve the outcome of patients.

\section{Materials and Methods Study Designs, Subjects, Site, Entry Criteria and Data Collection}

A prospective, descriptive cross-sectional study was conducted at Department of Infectious Diseases, Military Hospital 103 and Institute of Clinical Infectious and Tropical Diseases, Military Central Hospital 108, Hanoi from May 2013 to June 2019, including 88 adult febrile patients caused by Orientia tsutsugamushi or Rickettsia spp. were enrolled. Of these, 50 were Orientia tsutsugamushi patients and 38 were Rickettsia spp. patients (including Rickettsia typhi and Rickettsia spp.). Eligible participants were performed clinical examination and investigations that consist of routine tests and recorded in a standard questionnaire form. Thereafter, the clinical presentation laboratory results were determined in each group of patients based on these above data.

\section{Inclusion Criteria}

All of the patients (aged 15 years and over) were hospitalized with the following criteria: Unidentified Acute Fever ( $\geq 3$ days); Clinical manifestations of suspected rickettsial infection, such as eschar and/or at least one of the following: Congestive skin, congestive conjunctiva, rash, lymphadenopathy, enlargement of the liver and/or spleen. The patient or legal guardian agreed to participate in the study.

The patient was diagnosed with rickettsial infection when all the above selection criteria were satisfied and had a positive real-time PCR detection of Rickettsiaceae.

\section{Exclusion Criteria}

Patients who had at least one of the following conditions were excluded from the study: Pregnancy, breastfeeding patients; Patients with fever that had clear evidence of other pathogens or non-infection, such as cancer, autoimmune system disease. Patients being diagnosed and treated for liver and kidney failure. Patients with HIV co-infection; Patients were not willing to participate in this study.

\section{Data Collection}

We recorded information regarding epidemiological characteristics (age, geography, residence, and occupation), medical history, clinical and subclinical findings, lifethreatening complications during treatment, outcomes and some factors predicting serious life-threatening complications in a case record form. We classified outcome at discharge as full recovery, death, or palliative discharge (patients were willed to die in their home with their family), time to defervescence and duration of hospitalization (days, mean) (Figure 1).

\section{Specimen Collection and Laboratory Testing}

A sterile cotton swab was inserted and swirled into the bottom of the eschar. The materials obtained on a cotton swab can be processed for DNA separation and subsequent 


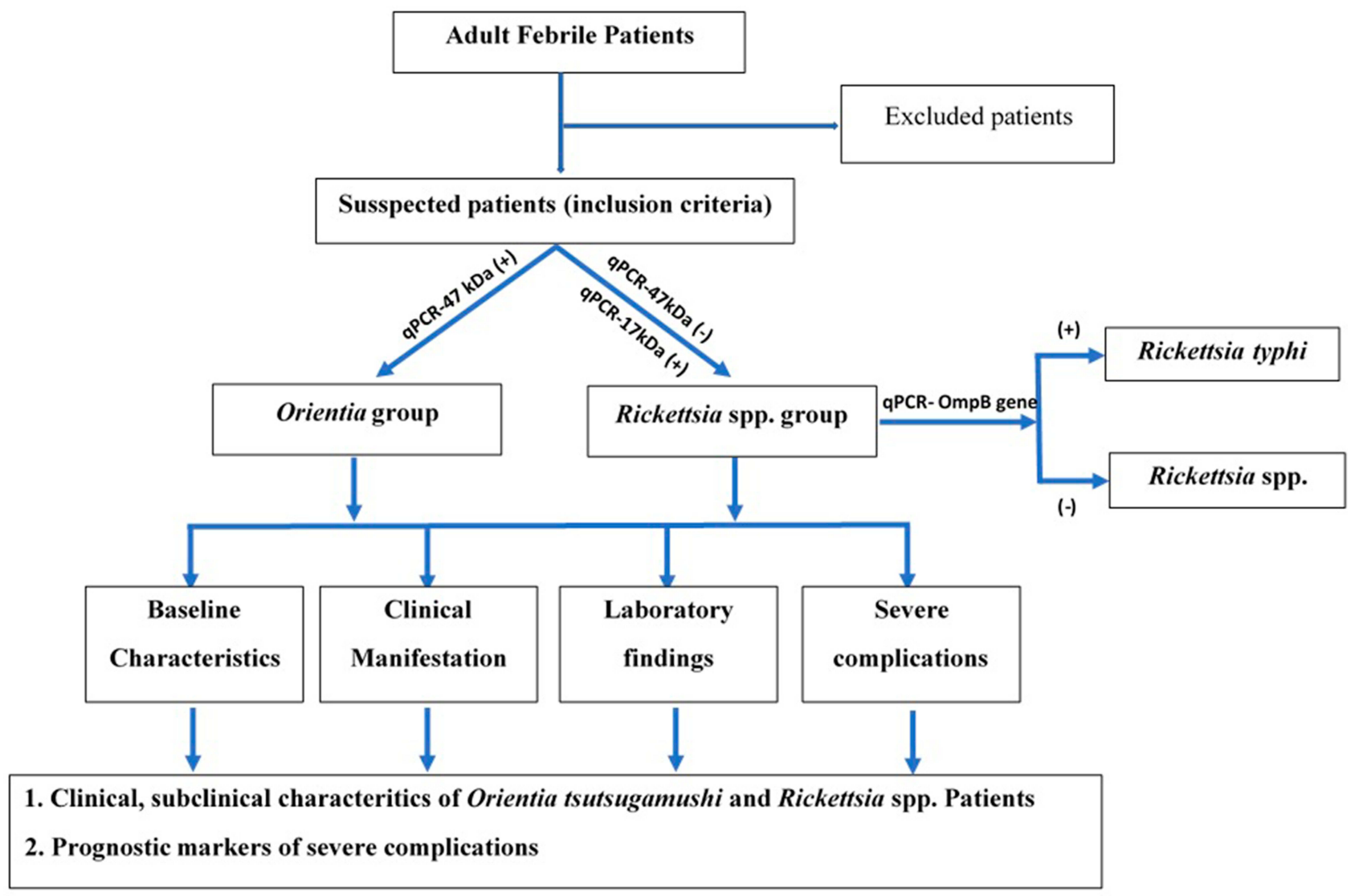

Figure I Study design flowchart.

PCR analysis. If the eschar is covered with a black scale, it must be removed prior to sampling as described above, and the black scale may also be processed for PCR analysis and diagnosis of Rickettsial pathogens.

The patient's blood was collected at admission according to the anticoagulation procedure and tested for blood culture and basic laboratory tests such as complete blood counts, biochemistry, procalcitonin, and serologic and molecular testing for rickettsioses.

\section{Quantitative Real-Time PCR Technique}

To differentiate Ricketsiaceae species, the primers and probes were designed to target specific sequences of $O$. tsutsugamushi (47 kDa gene encoding outer membrane protein), Rickettsia spp. (17 kDa gene encoding outer membrane proteins) and OmpB protein-coding gene of R.typhi (The sequence of primers and probes is provided in Table S1).

Whole blood was collected in EDTA tubes, then processed it with blood genomic DNA isolation Mini Kit (https://norgenbiotek.com/product/blood-dna-isolation-mini -kit) according to the manufacturer's instructions and previously described assays to extract DNA. Bacteria DNA were extracted from tissue (eschar, swab) using the DNA EZ1 extraction kit (https://www.qiagen.com, Cat No./ID: 953034) according to the manufacturer's instructions.

For each qPCR assay, we extracted $5 \mu \mathrm{L}$ of bacteria DNA sample and added it to a final reaction volume of $25 \mu \mathrm{L}$, using QIAGEN Multiplex PCR Kit (https://www.qiagen.com, Cat No./ID: 206143), and performed real-time PCR on an AriaMx Real-time PCR System (Agilent, USA) at Department of Molecular Biology, Military Central Hospital 108 (The protocol is provided in Table S2 $-\underline{3}$ and Figure S1).

\section{Ethical Statement}

This study was approved by the Ethical Committees of Vietnam Military Medical University (No.150/2013/CNHĐĐÐ). All patients provided written informed consent, and that this study was conducted in accordance with the Declaration of Helsinki.

\section{Statistical Analysis}

The Fisher exact test was used to compare clinical characteristics among different groups. Variables with a normal distribution were expressed as the mean \pm standard 
deviation (SD) and compared them using the analysis of variance test for 2-group comparisons. Two groups of patients with and without life-threatening complications were compared to determine which variables were different statistically. Then, the "categorical variables" were taken into Univariable analysis to calculate Odd Ratio (OR) and somehow evaluated their value in differentiating 2 groups. The continuous variables underwent ROC analysis to calculate the Area Under Curve (AUC) using the method presented by DeLong. ${ }^{17}$ Variable had AUC $>0.9$ or between 0.8 and 0.9 or from 0.7 to 0.8 was excellent, good, fair, respectively, in prognosticating patients with Rickettsiaceae.

\section{Results}

\section{Patient Demographic, Clinical Manifestations in Patients with Rickettsiaceae}

We enrolled 50 scrub typhus patients and 38 cases with rickettsioses from May 2013 to June 2019. The average age of Orientia group was $52.1 \pm 17.9$ and Rickettsia spp. patients was $49.5 \pm 14.5$. There are no significant differences between the average ages of 2 groups. Males were more occupied in both groups of patients $(62 \%$ and $63.2 \%$, respectively). Famer $(28.0 \%)$ and self-employed person $(30 \%)$ accounted for the majority of scrub typhus patients while students $(36.8 \%)$ and self-employed person $(36.8 \%)$ accounted for the majority of rickettsioses patients. Patients with Orientia infection were more prevalent in non-urban area $(64 \%)$ and out of Hanoi (70\%) while Rickettsioses patients were more prevalent in Urban area $(68.4 \%)$ and within Hanoi city. The proportion of patients who had exposed to forest was $33.0 \%$ overall, in which $20.0 \%$ of the scrub typhus group.

Patients with scrub typhus were mainly diagnosed on the first and second days. after admission (accounted for $72 \%$ of the total number of patients with scrub typhus). Rickettsioses patients were diagnosed later at day 3 (accounting for 28.6\%), and after day 5 (accounting for $31.5 \%$ )

The total duration of fever for scrub typhus $(12.68 \pm$ $5.10)$ days was significantly longer $(p=0.028)$ than that of Rickettsial infected patients $(10.63 \pm 2.68)$ days. The number of fever patients with ague or chills in the scrub typhus group was higher than that of the Rickettsial fever group $(84 \%$ and $18 \%$ vs $71.1 \%$ and $7.9 \%$, respectively), however this difference was not statistically significant.

Skin-mucosal lesions, endothelial sagging system involvements were more common in the scrub typhus group with eschar (70\%), skin-conjunctiva congestion $(60 \%)$, lymphadenopathy (44\%). In contrast, Rickettsia patients had a higher rate of maculopapular rash $(39.5 \%)$.

There were $6 \%$ of mortality in the group of scrub typhus patients. The mean time of defervescence was $2.70 \pm 2.06$ with mean of duration in hospital was $9.36 \pm$ 2.62. The corresponding number in the group of Rickettsia patients were $0 \%, 2.00 \pm 1.12$ and $9.13 \pm 2.60$, respectively. There were no significant differences in terms of outcomes in 2 groups of patients (Table 1).

\section{Laboratory Test Results of Patients with Rickettsiaceae}

Of 88 enrolled Rickettsiaceae patients, 50 (56.8\%) tested samples had qPCR positive with Orientia tsutsugamushi, 38 (43.2\%) had qPCR-confirmed genus Rickettsia, of which R.typhi were accounted for $15.8 \%$ (6/38).

The leukocyte percentage of scrub typhus (48\%) was significantly higher than the other Rickettsia group (13.5\%) with $\mathrm{p}<0.002$. Thrombocytopenia is a common finding in both disease groups with the incidence of $70 \%$ and $76.3 \%$ respectively. Patients with scrub typhus had a higher incidence of anemia (34\%) and was more severe; however, the difference was not statistically significant.

Increased liver enzyme $>40 \mathrm{UI} / \mathrm{L}$ was a common finding in both groups of patients (over $88 \%$ of patients with scrub typhus and more than $94.7 \%$ of patients with Rickettsial fever), mostly with a slight increase (80-200 UI/L). The group of patients with scrub typhus had higher levels of liver enzymes than Rickettsial infections; however, the difference was not statistically significant.

Hypoalbuminemia was more common in the Orientia group $(73 \%)$ compared to $56.5 \%$ in the Rickettsia group, however the difference was not statistically significant. About $30 \%$ of patients in both groups had hyperbilirubinemia. Prolonged prothrombin time was not common in both groups of patients.

PCT increase $>0.05 \mathrm{ng} / \mu \mathrm{L}$ was recorded in $100 \%$ of patients in the two groups, in which the increase in PCT of 
Table I Demographic Characteristics and Clinical Manifestations of Patients with Rickettsiaceae

\begin{tabular}{|c|c|c|c|c|}
\hline Characteristics & $\begin{array}{l}\text { Orientia Cases } \\
(n=50)\end{array}$ & Rickettsia Cases $(\mathrm{n}=38)$ & $\begin{array}{l}\text { No. of Patients } \\
(n=88)\end{array}$ & p-value \\
\hline Age $(y)^{¥}$ & $52.1 \pm 17.9$ & $49.5 \pm 14.5$ & $51.0 \pm 16.5$ & $>0.05$ \\
\hline No. (\%) male & $31(62.0)$ & $24(63.2)$ & $55(62.5)$ & $>0.05$ \\
\hline \multicolumn{5}{|l|}{ Occupation } \\
\hline No. (\%) farmer & $14(28.0)$ & $3(7.9)$ & $17(19.3)$ & $>0.05$ \\
\hline No. (\%) self-employed person & $15(30.0)$ & $14(36.8)$ & $29(32.0)$ & \\
\hline No. (\%) Officer, student & $8(16.0)$ & $14(36.8)$ & $22(25.0)$ & \\
\hline No. (\%) soldier & II (22.0) & $3(7.9)$ & $14(15.9)$ & \\
\hline \multicolumn{5}{|l|}{ Place of residence (\%) } \\
\hline Hanoi city & $15(30.0)$ & $26(68.4)$ & $4 \mid(46.6)$ & $<0.00 \mathrm{I}^{\#}$ \\
\hline Out of Hanoi city & $35(70.0)$ & $12(3 \mid .6)$ & $47(53.4)$ & \\
\hline Urban & $18(36.0)$ & $26(68.4)$ & $44(50.0)$ & $0.003^{\#}$ \\
\hline Non-urban & $32(64.0)$ & $12(31.6)$ & $44(50.0)$ & \\
\hline \multicolumn{5}{|l|}{ Exposure to forest (\%) } \\
\hline Gardening, farming & $8(16.0)$ & $3(7.9)$ & II (I2.5) & 0.028 \\
\hline Outdoor activities & $12(24.0)$ & $7(18.4)$ & $19(21.6)$ & \\
\hline Abundance of trees around the house & $20(40.0)$ & $9(23.7)$ & $29(33.0)$ & \\
\hline Unknown & $10(20.0)$ & $19(50)$ & $29(33.0)$ & \\
\hline \multicolumn{5}{|l|}{ Fever } \\
\hline Before admission $\leq 7$ days & $24(48.0)$ & $29(76.3)$ & $53(60.23)$ & 0.007 \\
\hline Before admission $>7$ days & $26(52.0)$ & $9(23.7)$ & $35(39.77)$ & \\
\hline Duration of fever $(d)^{*}$ & $12.68 \pm 5.10$ & $10.63 \pm 2.68$ & $11.76 \pm 4.30$ & $0.028^{\#}$ \\
\hline Eschar (\%) & $35(70.0)$ & I (2.6) & $36(40.9)$ & $<0.001^{\#}$ \\
\hline Lymphadenopathy (\%) & $22(44)$ & 0 & $22(25)$ & $<0.00 \mathrm{I}^{\#}$ \\
\hline Congested skin/eyes (\%) & $30(60)$ & $12(31.6)$ & $42(47.7)$ & $0.008^{\#}$ \\
\hline Maculopapular rash (\%) & $10(20)$ & $15(39.5)$ & $25(28.4)$ & $0.045^{\#}$ \\
\hline Edema (\%) & $2(4)$ & $0(0)$ & $2(2.3)$ & $>0.05^{\# \#}$ \\
\hline Skin hemorrhage (\%) & I (2) & $0(0)$ & $\mathrm{I}(\mathrm{I} . \mathrm{I})$ & $>0.05^{\# \#}$ \\
\hline Hepatomegaly (\%) & $5(10.0)$ & $3(7.9)$ & $8(9.1)$ & $>0.05^{\# \#}$ \\
\hline Splenomegaly (\%) & $4(10.3)$ & $4(11.8)$ & $8(11.0)$ & $>0.05^{\# \#}$ \\
\hline \multicolumn{5}{|l|}{ Outcomes (\%) } \\
\hline Death, palliative discharge & $3(6)$ & 0 & $3(03.4)$ & $>0.05$ \\
\hline Recovery & $47(94)$ & $38(100)$ & $85(96.6)$ & \\
\hline Defervescence mean time ${ }^{*}$ & $2.70 \pm 2.06$ & $2.00 \pm 1.12$ & - & $>0.05$ \\
\hline Mean of duration in hospital ${ }^{¥}$ & $9.36 \pm 2.62$ & $9.13 \pm 2.60$ & - & $>0.05$ \\
\hline
\end{tabular}

Notes: Values are $\mathrm{n}(\%)$; p-values are from nonparametric trend testing across ordered groups. ${ }^{*}$ Values are mean \pm SD. ${ }^{~}$ Chi-square test. ${ }^{\#}$ Fisher exact test.

Rickettsia group $(\bar{X} \pm \mathrm{SD}: 0.926 \pm 0.45)$ was statistically lower than for scrub typhus group $(\bar{X} \pm \mathrm{SD}: 2.396 \pm 2.119)$ with $\mathrm{p}=0.026$. Increased CRP was also a common manifestation in both Rickettsial and Orientia disease groups, in which patients with scrub typhus have higher CRP levels than those of Rickettsia.

About renal function, patients with uremia were significantly higher in the Orientia group than in the Rickettsia group $(\mathrm{p}=0.004)$. However, patients with increased creatinine levels were similar in both groups.
Most of the patients in both groups had hyponatremia and hypokalemia, however the difference was not statistically significant (Table 2).

\section{The Life-Threatening Complications in the Course of Illness}

There was more life-threatening complications in Orientia group with $12 \%$ of patients had respiratory failure, $8 \%$ of patients had septic shock, $8 \%$ of patients had meningoencephalitis and $8 \%$ of patients had acute kidney injury. The 
Table 2 Laboratory Findings in Patients with Rickettsiaceae

\begin{tabular}{|c|c|c|c|c|}
\hline Variables & $\begin{array}{l}\text { Orientia Cases } \\
(n=50)\end{array}$ & $\begin{array}{l}\text { Rickettsia Cases } \\
(n=38)\end{array}$ & $\begin{array}{l}\text { No. of Patients } \\
(n=88)\end{array}$ & p-value \\
\hline $\mathrm{Hb}(g / l) *$ & $125.06 \pm 20.99$ & $133.69 \pm 14.24$ & $128.19 \pm 18.08$ & 0.036 \\
\hline Leukocyte count $\left(\times 10^{9} / \mathrm{L}\right){ }^{¥}$ & $9.44 \pm 3.33$ & $7.18 \pm 3.26$ & $8.46 \pm 3.30$ & 0.002 \\
\hline Platelets $\left(\times 10^{9} / \mathrm{L}\right) ~ ¥$ & $14 \mid \pm 100$ & $142 \pm 125$ & $|4| .43 \pm 110.80$ & $>0.05$ \\
\hline Serum AST $(\mathrm{UI} / \mathrm{L})>40$ & $46(92.0)$ & $36(94.7)$ & $82(93.2)$ & $>0.05$ \\
\hline Serum ALT $(\mathrm{UI} / \mathrm{L})>40$ & $44(88.0)$ & $36(94.7)$ & $80(90.9)$ & $>0.05$ \\
\hline Albumin $(g / l)^{\dagger ¥}$ & $30.92 \pm 6.93$ & $34.14 \pm 3.10$ & $32.15 \pm 5.46$ & $0.043^{\#}$ \\
\hline Prothrombin (\%) & $91.92 \pm 23.96$ & $96.50 \pm 13.52$ & $93.87 \pm 19.52$ & $>0.05$ \\
\hline Bilirubin $(\mu \mathrm{mol} / \mathrm{l})$ & $17.59 \pm 14.57$ & $13.88 \pm 9.90$ & $16.02 \pm 15.03$ & $>0.05$ \\
\hline $\operatorname{CRP}(\mathrm{mg} / \mathrm{L})^{\dagger \dagger ¥}$ & $72.41 \pm 55.42$ & $21.70 \pm 29.27$ & $65.17 \pm 51.68$ & $>0.05$ \\
\hline РCT $(\mathrm{ng} / \mathrm{mL})^{\phi \neq}$ & $2.396 \pm 2.119$ & $0.926 \pm 0.45 \mathrm{I}$ & $1.72 \pm 1.73$ & 0.026 \\
\hline Urea $>7.5 \mathrm{mmol} / \mathrm{L}$ & $10(20.4)$ & $0(0)$ & $10(11.8)$ & $0.004^{\# \#}$ \\
\hline Creatinine $>110 \mu \mathrm{mol} / \mathrm{L}$ & $4(8.2)$ & $2(5.6)$ & $6(7.1)$ & $>0.05$ \\
\hline Natri (mmol/L) & $131.73 \pm 4.46$ & $133.06 \pm 3.10$ & $132.29 \pm 3.89$ & $>0.05$ \\
\hline Kali (mmol/L) & $3.74 \pm 0.45$ & $3.77 \pm 0.34$ & $3.75 \pm 0.40$ & $>0.05$ \\
\hline
\end{tabular}

Notes: Values are n (\%); P-values are from nonparametric trend testing across ordered groups. ${ }^{\dagger} 60$ cases; ${ }^{\dagger \dagger} \mid 4$ cases; ${ }^{\phi 48}$ cases; ${ }^{\sharp}$ Mean \pm sD; ${ }^{\#}$ Chi-square test, ${ }^{\# \#}$ Fisher exact test.

Abbreviations: ALT, alanine aminotransferase; AST, aspartate aminotransferase; Hb, hemoglobin; CRP, c-reactive protein; PCT, procalcitonin.

corresponding number in Rickettsia group were $0 \%, 0 \%$, $7.9 \%$ and $5.3 \%$, respectively.

\section{Prognostic Markers of Severe Complications in Patients with Rickettsial Infection}

In Table 3, 15/88 (17.04\%) patients had one of 4 lifethreatening complications (including respiratory failure, septic shock, encephalitis-meningitis and acute kidney injury). There were significant differences between 2 groups in term of patients with dyspnea, increased respiratory rate $>25$, Coarse crackles, mean of hematocrit, mean of hemoglobin, leukocytosis, AST $>200 \mathrm{UI} / \mathrm{L}$, mean of bilirubin, mean of PCT, bilateral infiltrate on chest X-ray, pleural effusion and visceral fluid. It is worthy to comment that there was no statistical significance between 2 groups for advanced age $>60$ years, and duration of fever before admission.

On univariable logistic regression analysis, there were some variables with high Odd ratio between 2 groups namely: Bilateral infiltrate $(\mathrm{OR}=19.5)$, coarse crackles $(\mathrm{OR}=18)$, respiratory rate $>25(\mathrm{OR}=18)$, dyspnea $(\mathrm{OR}=7.44)$, pleural effusion on ultrasound (OR $=4.3)$; AST $>200 \mathrm{UI} / \mathrm{L}(\mathrm{OR}=$ 4.42); visceral fluid on ultrasound ( $\mathrm{OR}=3.86$ ) (Table 4).

On ROC analysis, PCT level had fair power to differentiate between 2 groups of patients with $\mathrm{AUC}=0.75$. The other variable had no usefulness to differentiate between 2 groups of patients (Table 5).
At PCT value $>4.4 \mathrm{ng} / \mathrm{mL}$, the specificity of PCT to predict severe complication was $94.4 \%$ however the sensitivity at this point was only $37.5 \%$ (Data was provided in Figure S2).

\section{Discussion}

Since all Rickettsioses were recommended to treat with Doxycycline, we did not attempt to identify the number of Rickettsia species prevalent in Vietnam. Our aim of study just confirmed some clinical profiles, laboratory findings and prognostic factors of severe complications in patients with rickettsial infection. We believe that our research will help local physicians to clinically distinguish and predict severe complications among patients with scrub typhus and Rickettsia spp.

Diagnosis of scrub typhus and rickettsioses is challenging for any clinician, especially when the patients are present without highly suspected symptoms such as eschar, rash, lymphadenopathy and in the low-income setting where physicians lack of diagnostic tools to confirm rickettsioses.

Skin-mucosal manifestations are generally considered as an indication of disease caused by Rickettsiaceae and distinguish some pathogens in the disease group caused by Rickettsiaceae. Our study showed that skin-mucosal and peripheral lymph node manifestations were more common in the scrub typhus group with typical eschar lesions (70\%), skin-conjunctiva congestion (60\%), lymphadenopathy 
Table 3 The Differences Between Complicated Group and Non-Complicated Group

\begin{tabular}{|c|c|c|c|}
\hline Study Variables & Non-Complication & Life-Threatening Complications ${ }^{a}$ & $\mathbf{p}$ \\
\hline Age $\geq 60$ & $23 / 73$ & $7 / 15$ & $>0.05$ \\
\hline Male gender & $44 / 73$ & $11 / 15$ & $>0.05$ \\
\hline Dyspnea $^{\mathrm{b}}$ & $6 / 73$ & $6 / 15$ & 0.001 \\
\hline Respiratory rate $\geq 25$ cycle/minutes ${ }^{b}$ & $1 / 73$ & $3 / 15$ & $0.015^{\#}$ \\
\hline Eschar & $29 / 73$ & $7 / 15$ & $>0.05$ \\
\hline Fine crackles & $17 / 73$ & $7 / 15$ & $>0.05$ \\
\hline Coarse crackles ${ }^{b}$ & $1 / 73$ & $3 / 15$ & 0.015 \\
\hline Mean of hematocrit ${ }^{b}$ & $0.392 \pm 0.046$ & $0.352 \pm 0.066$ & 0.009 \\
\hline Mean of hemoglobin ${ }^{b}$ & $131.06 \pm 16.97$ & $116.23 \pm 23.74$ & 0.008 \\
\hline Leukocytosis(x $\left.10^{9} / L\right){ }^{b}$ & $20 / 73$ & $9 / 15$ & $0.014^{\#}$ \\
\hline Thrombocytopenia(x109/L) & $52 / 73$ & $12 / 15$ & $>0.05$ \\
\hline AST $\geq 200 \mathrm{UI} / \mathbf{L}^{\mathrm{b}}$ & $15 / 73$ & $8 / 15$ & 0.008 \\
\hline$A L T \geq 200 \mathrm{UI} / \mathrm{L}$ & $13 / 73$ & $4 / 15$ & $>0.05$ \\
\hline Bilirubin $>34 \mu \mathrm{mol} / \mathrm{l}$ & $3 / 65$ & $2 / 15$ & $>0.05$ \\
\hline Bilirubin total $^{\mathrm{b}}$ & $14.40 \pm 11.15$ & $24.17 \pm 22.63$ & 0.033 \\
\hline Albumin $<35 \mathrm{~g} / \mathrm{l}$ & 30 & 9 & $>0.05$ \\
\hline PCT (ng/mL) ${ }^{b}$ & $1.32 \pm 1.08$ & $3.23 \pm 3.05$ & 0.013 \\
\hline Unilateral infiltrate & $5 / 66$ & $3 / 13$ & $>0.05$ \\
\hline Bilateral infiltrate $^{\mathrm{b}}$ & $1 / 66$ & $3 / 13$ & 0.013 \\
\hline Pleural effusion on chest $X$-ray & $9 / 66$ & $2 / 13$ & $>0.05$ \\
\hline Pleural effusion ${ }^{\mathrm{b}}$ & $10 / 62$ & $5 / 11$ & 0.027 \\
\hline Visceral fluid ${ }^{\mathrm{b}}$ & $11 / 62$ & $5 / 11$ & 0.041 \\
\hline
\end{tabular}

Notes: The bold values in the table mean the variables are statistically different that would go further step to calculate the Odd Ratio in the next table. ${ }^{\text {ancluded respiratory }}$ failure, septic shock, meningoencephalitis, acute kidney injury. ${ }^{b}$ Variables are different statistically. ${ }^{\#}$ Chi-square test.

Table 4 Univariable Logistic Regression Analysis

\begin{tabular}{|l|l|l|l|l|}
\hline Study Variables $^{\mathbf{b}}$ & Non-Complication & $\begin{array}{l}\text { Life-Threatening } \\
\text { Complications }^{\mathbf{a}}\end{array}$ & P & OR \\
\hline Dyspnea & $6 / 73$ & $6 / 15$ & 0.003 & 7.44 \\
Respiratory rate $\geq 25$ cycle/minutes & $1 / 73$ & $3 / 15$ & 0.016 & 18 \\
Coarse crackles & $1 / 73$ & $3 / 15$ & 0.016 & 18 \\
Leukocytosis & $20 / 73$ & $9 / 15$ & 0.019 & 3.97 \\
AST $\geq 200$ (UI/L) & $15 / 73$ & $8 / 15$ & 0.012 & 4.42 \\
Bilateral infiltrate & $1 / 66$ & $3 / 13$ & 0.014 & 19.5 \\
Pleural effusion & $10 / 62$ & $5 / 11$ & 0.035 & 4.3 \\
Visceral fluid & $11 / 62$ & $5 / 11$ & 0.05 & 3.86 \\
\hline
\end{tabular}

Notes: ${ }^{a}$ Included respiratory failure, septic shock, meningoencephalitis, acute kidney injury. ${ }^{\text {b } V a r i a b l e s ~ a r e ~ s t a t i s t i c a l l y ~ d i f f e r e n t ~ t h a t ~ c o m e ~ f r o m ~ T a b l e ~} 3$.

$(44 \%)$. It is worth noting that, in this study, no patient with fever caused by Rickettsia had eschar. This result is similar to Thuy PT, ${ }^{18}$ as well as A. Aouam et al. ${ }^{19}$ This all proved that eschar is a valuable symptom for distinguishing 2 groups of diseases. However, it must be kept in mind that the presence of eschar in patients with scrub typhus is very different. For instance, eschar had been documented in 36 of $74(46 \%)$ American servicemen in Southern Vietnam, ${ }^{20}$ however, another study found a prevalence of $60 \%$ to $88 \% .^{21}$ Eschar may be missed if physical examinations are not done carefully, including genital examination and skin folds under the breast investigation. 
Table 5 The Area Under Curve (AUC) of Some Variables to Predict Severe Complications

\begin{tabular}{|l|l|l|l|l|}
\hline Study Variables $^{\mathbf{b}}$ & Non-Complication & Life-Threatening Complications $^{\mathbf{a}}$ & $\mathbf{p}$ & AUC $^{-}$ \\
\hline Hematocrit & $0.392 \pm 0.046$ & $0.352 \pm 0.066$ & 0.009 & 0.40 \\
$\mathrm{Hb}$ & $131.06 \pm 16.97$ & $116.23 \pm 23.74$ & 0.008 & 0.43 \\
PCT $^{\mathbf{c}}$ & $1.32 \pm 1.08$ & $3.23 \pm 4.05$ & $\mathbf{0 . 0 1 3}$ & $\mathbf{0 . 7 5}$ \\
Bilirubin total & $14.40 \pm 11.15$ & $24.17 \pm 27.63$ & 0.033 & 0.67 \\
\hline
\end{tabular}

Notes: The bold values are statistically different $(p<0.013)$ that would be able to distinguished between the two groups with quite high reliability

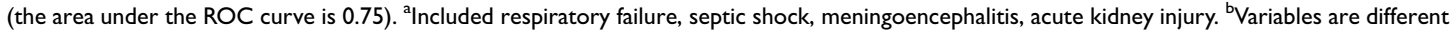
statistically that come from Table 3. 'Valuable inflammation marker.

Although maculopapular rash has been described as the classic symptom of Orientia, but in our study Rickettsia group had a significantly higher incidence of maculopapular rash (39.5\%). This result is consistent with the study of Thuy PT and is similar to the study about murine typhus in foreign authors with the opinion. ${ }^{18,22-24}$

Peripheral lymphadenopathy is well known as one of the triages to diagnosis scrub typhus. Regional lymph nodes usually appear with fever or 2-3 days after fever. It is the discovery of regional lymph nodes that guides physician to investigate eschar. In our study, $44 \%$ of scrub typhus patients had peripheral lymphadenopathy, and this sign was not seen in any patient with Rickettsial fever. It is an agreement with Harrison's principles about the Rickettsiaceae family, enlarged lymph nodes were not recorded in the group of Flea-borne spotted fever and endemic typhus (murine typhus). ${ }^{13}$ Peripheral lymph node detection rate in our research group was higher than that of Jung HC (7.3\%), Dien VM (23.4\%), Yun JH et al $(15 \%)$ but lower than that of Thuy PT. (63.7\%), Lakshmanan S (96\%). ${ }^{18,24-27}$ The difference is probably due to differences in the study population and the time when the patients were admitted to hospitals and may be due to the criteria for identifying enlarged lymph nodes of each author.

About laboratory findings, thrombocytopenia was a common manifestation of both Rickettsial fever and scrub typhus with $70 \%$ and $76.3 \%$, respectively. The difference was not statistically significant with $p>0.05$. Our study once again confirms that thrombocytopenia is a common hematological disorder in patients with bacterial fever of the Rickettsiaceae family. Physiologically, the bacteria of the Rickettsiaceae family mainly invade vascular endothelial cells causing microvascular damage, stimulating the consumption of platelets leading to thrombocytopenia. The degree of thrombocytopenia was a major prognostic factor in the research of Thuy PT, ${ }^{18}$ Sharma R et al. ${ }^{28}$ Min-Chul Kim et al. ${ }^{29}$ Though it is very rare that patient develops deep vein thrombosis (DVT) in rickettsial infection, there are reported cases where rickettsial infection leads to hypercoagulable state leading to disseminated intravascular coagulation (DIC) and $D V T$ in severe infection cases during acute phase. $^{30}$

On univariable logistic regression analysis, the result of this study once again confirms the value of the aforementioned clinical symptoms in the early detection of serious complications and timely treatment in order to prevent more severe complications. On ROC analysis, PCT values should be combined with other variables to predict the likelihood of complications in patients with rickettsioses.

Our study has some limitations. Firstly, the study was carried out at 2 central hospitals (Military Hospital 103 and Military Central Hospital 108) where patients on treatment are usually severe and transferred from the local facilities. Secondly, due to the limitation of retrospective results, only typical patients and sufficient medical records were selected for the study. Therefore, all the results of the study may not fully represent the clinical manifestation of Rickettsial disease. Last but not least, the number of cases with murine typhus in our study was small, so it is not statistically significant to analyze the clinical picture of each Rickettsia species.

In conclusion, eschar and peripheral lymphadenopathy were two valuable clinical symptoms for the diagnosis of scrub typhus and distinguishing 2 groups of diseases. Level of PCT was able to use as a major inflammation marker in combination with other subclinical variables to prognosticate severe complications of Rickettsial diseases.

\section{Ethical Statement}

This study was approved by the Ethical Committees of Vietnam Military Medical University (No.150/2013/CNHĐĐĐ). All patients provided written informed consent, 
and that this study was conducted in accordance with the Declaration of Helsinki.

\section{Acknowledgments}

We are grateful to all the patients who voluntarily participated in this study, the doctors and nurses of Military Hospital 103 and Military Central Hospital 108 for their generous support of this study.

\section{Author Contributions}

All authors made substantial contributions to conception and design, acquisition of data, or analysis and interpretation of data; took part in drafting the article or revising it critically for important intellectual content; gave final approval of the version to be published; and agree to be accountable for all aspects of the work.

\section{Funding}

The author(s) received no financial support for the research, authorship, and/or publication of this article.

\section{Disclosure}

The author(s) declared no potential conflicts of interest with respect to the research, authorship, and/or publication of this article.

\section{References}

1. Parola P, Paddock CD, Socolovschi C, et al. Update on tick-borne rickettsioses around the world: a geographic approach. Clin Microbiol Rev. 2013;26(4):657-702.

2. Sachman-Ruiz B, Quiroz-Castañeda RE. Genomics of Rickettsiaceae: an update. Farm Anim Dis Recent Omic Trends New Strategies Treat. 2018:83.

3. Izzard L, Fuller A, Blacksell SD, et al. Isolation of a novel Orientia species (O. chuto sp. nov.) from a patient infected in Dubai. $J$ Clin Microbiol. 2010;48(12):4404-4409. doi:10.1128/JCM.01526-10

4. Azad AF, Beier-Sexton M, Gillespie JJ. The family Rickettsiaceae. In: Emmanuel Goldman LHG, editor. Practical Handbook of Microbiology. CRC Press; 2015:445.

5. Blanton LS, Walker DH. The Rickettsiaceae, Anaplasmataceae, and Coxiellaceae. Manual Mol Clin Lab Immunol. 2016:461-472.

6. CDC. Tickborne disease surveillance data summary. In: National Center for Emerging and Zoonotic Infectious Diseases (NCEZID) Dov-BDD. ed2019.

7. Vu Trung N, Thuong NTH, Toan TK, et al. Seroprevalence of scrub typhus, typhus, and spotted fever among rural and urban populations of northern Vietnam. Am J Trop Med Hyg. 2017;96(5):1084-1087. doi:10.4269/ajtmh.16-0399

8. Le-Viet N, Le V-N, Chung H, et al. Prospective case-control analysis of the aetiologies of acute undifferentiated fever in Vietnam. Emerg Microbes Infect. 2019;8(1):339-352. doi:10.1080/22221751.2019.1580539

9. Trung NV, Le Thi Hoi VMD, Huong DT, et al. Clinical manifestations and molecular diagnosis of scrub typhus and murine typhus, Vietnam, 2015-2017. Emerg Infect Dis. 2019;25(4):633. doi:10.3201/eid2504. 180691
10. Biggs HM, Behravesh CB, Bradley KK, et al. Diagnosis and management of tickborne rickettsial diseases: Rocky Mountain spotted fever and other spotted fever group rickettsioses, ehrlichioses, and anaplasmosis-United States: a practical guide for health care and public health professionals. Morb Mortal Wkly Rep. 2016;65(2):1-44.

11. Abdad MY, Abdallah RA, Fournier P-E, Stenos J, Vasoo S, Kraft CS. A concise review of the epidemiology and diagnostics of Rickettsioses: Rickettsia and Orientia spp. $J$ Clin Microbiol. 2018;56(8):e01728-01717. doi:10.1128/JCM.01728-17

12. Blanton LS. The Rickettsioses: a practical update. Infect Dis Clin. 2019;33(1):213-229. doi:10.1016/j.idc.2018.10.010

13. Kasper L. Harrisons Manual of Medicine 19th. McGraw-Hill Education; 2016.

14. Rocky CDC Mountain spotted fever (RMSF): epidemiology and statistics. Available from: https://www.cdc.gov/rmsf/stats/index.html. Accessed June 6, 2020. Published 2019.

15. Regan JJ, Traeger MS, Humpherys D, et al. Risk factors for fatal outcome from Rocky Mountain spotted fever in a highly endemic area-Arizona, 2002-2011. Clin Infect Dis. 2015;60(11):1659-1666. doi:10.1093/cid/civ116

16. Binder A, Peterson AE, Armstrong P. Characteristics, treatment patterns, and outcomes of outpatients with Rickettsial diseases in a large, commercially insured population: United States, 2005-2016. Paper presented at: Open Forum Infectious Diseases. 2018.

17. Er D, DeLong DM, Clarke-Pearson DL. Comparing the areas under two or more correlated receiver operating characteristic curves: a nonparametric approach. Biometrics. 1988;44(3):837-845. doi:10. 2307/2531595

18. Thuy PT. Studying Clinical Characteristics, Methods of Diagnosis and Treatment of Scrub Typhus. Hanoi Medical University; 2007.

19. Aouam A, Toumi A, Ben Brahim H, et al. Epidemiological, clinical and laboratory features of murine typhus in central Tunisia. Med Mal Infect. 2015;45(4):124-127. doi:10.1016/j.medmal.2015.01.009

20. Berman SJ, Kundin WD. Scrub typhus in South Vietnam: a study of 87 cases. Ann Intern Med. 1973;79(1):26-30. doi:10.7326/00034819-79-1-26

21. Sheehy TW, Hazlett D, Turk RE. Scrub typhus: a comparison of chloramphenicol and tetracycline in its treatment. Arch Intern Med. 1973;132(1):77-80. doi:10.1001/archinte.1973.03650070069010

22. Nadjm B, Thuy PT, Trang VD, Dang Ha L, Kinh NV, Wertheim HF. Scrub typhus in the northern provinces of Vietnam: an observational study of admissions to a national referral hospital. Trans $R$ Soc Trop Med Hyg. 2014;108(11):739-740. doi:10.1093/trstmh/tru145

23. Hamaguchi S, Cuong NC, Tra DT, et al. Clinical and epidemiological characteristics of scrub typhus and murine typhus among hospitalized patients with acute undifferentiated fever in Northern Vietnam. Am J Trop Med Hyg. 2015;92(5):972-978. doi:10.4269/ajtmh.14-0806

24. Dien VM. Clinical, Subclinical Characteristics and Treatment Results of Rickettsial Infection at National Hospital for Tropical Diseases (3/2015 - 3/2018). Hanoi Medical University; 2019.

25. Lakshmanan S, Sagayaraj B, Sujatha B, Vasudevan LD. Clinical and laboratory profile of pediatric scrub typhus in a tertiary care teaching hospital in Southern India. Int J Contemp Pediatr. 2018;5(5):2092. doi:10.18203/2349-3291.ijcp20183875

26. Yun JH, Hwang HJ, Jung J, et al. Comparison of chest radiographic findings between severe fever with thrombocytopenia syndrome and scrub typhus: single center observational cross-sectional study in South Korea. Medicine. 2019;98(46):e17701. doi:10.1097/MD.0000 000000017701

27. Jung H-C, Chon S-B, Oh WS, Lee D-H, Lee H-J. Etiologies of acute undifferentiated fever and clinical prediction of scrub typhus in a non-tropical endemic area. Am J Trop Med Hyg. 2015;92(2):256-261. doi:10.4269/ajtmh.14-0377

28. Sharma R, Krishna V, Manjunath HS, et al. Analysis of two outbreaks of scrub typhus in Rajasthan: a clinico-epidemiological study. $J$ Assoc Phys India. 2014;62:24-29. 
29. Kim M-C, Chong YP, Lee S-O, et al. Differentiation of severe fever with thrombocytopenia syndrome from scrub typhus. Clin Infect Dis. 2018;66(10):1621-1624. doi:10.1093/cid/cix1119
30. Honnutagi RM, Reddy KS, Biradar M, Patil SS. Deep vein thrombosis-a complication of Rickettsial fever. Int $J$ Res Rev. 2019;6(8):177-180.

\section{Publish your work in this journal}

Infection and Drug Resistance is an international, peer-reviewed openaccess journal that focuses on the optimal treatment of infection (bacterial, fungal and viral) and the development and institution of preventive strategies to minimize the development and spread of resistance. The journal is specifically concerned with the epidemiology of antibiotic resistance and the mechanisms of resistance development and diffusion in both hospitals and the community. The manuscript management system is completely online and includes a very quick and fair peerreview system, which is all easy to use. Visit http://www.dovepress.com/ testimonials.php to read real quotes from published authors. 